\section{Qualidade de vida de portadores de HIV/AIDS e sua relação com linfócitos CD4+, carga viral e tempo de diagnóstico}

\section{Quality of life of people living with HIV/AIDS and its relationship with CD4+ lymphocytes, viral load and time of diagnosis}

\section{Brunno Elias Ferreira'}

Isabele Mendes Oliveira"

Anamaria Mello Miranda Paniago"'I

' Faculdade Unigran Capital.

" Departamento de DST/AIDS.

III Universidade Federal de Mato Grosso do Sul (UFMS), FAMED.

\section{Resumo}

A qualidade de vida (QV) acompanha o tratamento dos pacientes com AIDS, juntamente com as inovações farmacológicas, que permitiram prolongar a vida do paciente e a manutenção de seu bem-estar. O presente estudo objetivou verificar a QV desses pacientes e correlacionar com dados clínicos e laboratoriais. Participaram 205 pacientes HIV/AIDS, os quais responderam ao questionário WHOQOL-120-HIV e tiveram coletados seus dados sociodemográficos, clínicos e laboratoriais. A média etária foi de 40,59 $\pm 11,81$ anos; contagem de linfócitos CD4+ de 397,97 $\pm 232,84 \mathrm{~mm}^{3}$ e 5,23 $\pm 3,94$ anos de diagnóstico do HIV. A carga viral era $<50$ cópias/ $\mathrm{ml} \mathrm{em} 115$ pacientes; em 61, entre 50 e 10.000; e em 29 acima de 10.000 cópias. Os domínios atingiram bons escores médios, sendo que o melhor foi o psicológico $(14,5 \pm 2,7)$, seguido de relações sociais $(13,7 \pm 2,2)$, físico $(12,7 \pm 3,5)$, nível de independência $(12,6 \pm 2,5)$, crenças pessoais $(12,4 \pm 2,4)$ e meio ambiente $(12,4$ $\pm 1,8$ ). Os melhores escores nas facetas dor, lazer, apoio social, ambiente físico e crenças pessoais foram os com maiores níveis de $\mathrm{CD} 4$ ( $\mathrm{p}<0,05)$. Já nas facetas finanças, lazer, preocupações sobre o futuro e QV geral e percepção de saúde foram em pacientes com carga viral $<50(\mathrm{p}<0,05)$. Os melhores índices nas facetas energia e fadiga, atividade sexual, informação e transporte, sintomas da doença, cuidados e preocupações sobre o futuro foram verificados em pacientes com menor tempo de diagnóstico $(\mathrm{p}<0,05)$. Os pacientes com HIV/AIDS do estudo apresentam QV de nível intermediário e associação com os níveis de CD4, CV e tempo de diagnóstico.

Palavras-chave: AIDS. OMS. HAART. Bemestar. Saúde. Epidemiologia. 


\section{Abstract}

Quality of life (QOL) has accompanied the treatment of AIDS patients, along with pharmacological innovations that have allowed patients to live longer and maintain their well-being. The present study aimed at evaluating the QOL of these patients and correlate it with clinical and laboratory data. The study included 205 patients with HIV/AIDS, who answered the WHOQOL-120-HIV; and whose socio-demographic data, clinical and laboratory findings were collected. The average age was $40.59 \pm 11.81$ years; CD4+ lymphocyte count, $397.9 \pm 232.84 \mathrm{~mm}^{3}$; and years of diagnosis of HIV, $5.23 \pm 3.94$. Viral load was $<50$ copies/ml in 115 patients; 50 to 10.000 in 61 ; and above 10.000 copies in 29 patients. Domains achieved satisfactory average scores, and the best were the psychological (14.5 \pm 2.7 ), followed by social relationships (13.7 \pm 2.2$)$, physical (12.7 \pm $3.5)$, independence (12.6 \pm 2.5$)$, personal beliefs (12.4 \pm 2.4$)$, and environment (12.4 \pm 1.8 ). The best scores on pain, pleasure, social support, physical environment, and personal belief facets were observed for those with higher CD4 levels ( $p<0.05)$. The best scores for the finance, leisure, concerns about the future, overall QOL, and perceived health facets were observed for patients with viral load $<50$ ( $\mathrm{p}<0.05)$. The highest rates for energy, fatigue, sexual activity, information, transportation, symptoms, care, and concerns about the future facets were seen in patients with less time of diagnosis ( $\mathrm{p}<$ $0.05)$. HIV/AIDS patients in the study had an intermediate QOL correlating to CD4 levels, $\mathrm{VL}$, and time of diagnosis.

Keywords: AIDS. WHO. HAART. Well-being. Health. Epidemiology.

\section{Introdução}

O surgimento da AIDS na década de 1980 foi marcado com grande sofrimento relacionado ao fato de ser uma doença grave e fatal e associada a contágio sexual e uso de drogas ilícitas, trazendo forte impacto psicológico ao portador da doença ${ }^{1}$.

Após três décadas, a doença apresenta características epidemiológicas e clínicas diferentes daquelas inicialmente observadas. Os avanços no diagnóstico e tratamento foram significativos e o Brasil tem se destacado no panorama internacional com a disponibilização dos medicamentos pelo sistema público de saúde ${ }^{2}$.

O tempo de sobrevida do paciente HIV/AIDS aumentou após a introdução da terapia antirretroviral de alta potência (HAART), a partir de $1996^{1,3}$. O tratamento inibe a replicação do HIV, proporcionando redução do RNA viral e, assim, observa-se a elevação dos linfócitos CD4+, células-alvo do HIV. A recuperação da imunidade nestes indivíduos garante maior sobrevida, já que diminuem os riscos de adoecimento por infecções oportunistas. Apesar de os medicamentos serem eficientes, os pacientes podem apresentar ampla manifestação de efeitos colaterais ${ }^{1}$.

A qualidade de vida (QV) de doentes crônicos tem sido preocupação da Organização Mundial da Saúde (OMS), que elaborou um instrumento para este fim, oWHOQOL- $100^{4}$, e mais recentemente um específico para pacientes HIV/AIDS, o WHOQOL-120-HIV 5 .

Os objetivos desse estudo foram analisar a QV de pacientes HIV/AIDS atendidos em serviço especializado no Estado de Mato Grosso do Sul (Brasil) e investigar sua associação com níveis de linfócitos CD4+, Carga viral do HIV e tempo de diagnóstico da infecção.

\section{Metodologia}

Foi realizado um estudo tipo corte transversal, no qual foi utilizada amostragem não-probabilística consecutiva ${ }^{6}$ de 
pacientes que frequentaram o hospital de referência do estudo de julho a outubro de 2008. Foram identificados 439 pacientes portadores de HIV em acompanhamento ambulatorial no Hospital-Dia Professora Esterina Corsini. Foi adotada prevalência de 50\% ( \pm 5\%), nível de significância de 5\% e $95 \%$ de confiança, resultando em amostra com 205 participantes. Foram elegíveis para a pesquisa os pacientes com exame confirmatório de infecção pelo HIV no prontuário médico; idade igual ou superior a 18 anos; que não tinham dificuldade de comunicação que comprometesse o entendimento do questionário; e participação voluntária no estudo assinando o Termo de Consentimento Livre e Esclarecido.

Para avaliação da QV foi utilizado o instrumento WHOQOL-120 HIV, já validado no Brasil para a língua portuguesa ${ }^{5}$. O WHOQOL-120 HIV tem seis domínios que representam as manifestações maiores da QV: físico, psicológico, nível de independência, relações sociais, meio ambiente e espiritualidade/religiosidade/crenças pessoais (ERCP). Cada domínio é composto por facetas, manifestações menores da QV, totalizando 29, sendo cinco específicas para pessoas vivendo com HIV/AIDS (PVHA) e uma sobre a QV geral. São 120 questões que devem ser respondidas em escala Likert, definindo intensidade. $\mathrm{O}$ instrumento foi aplicado por meio de entrevista ${ }^{4,5,7}$.

As questões formuladas negativamente no WHOQOL-120 HIV foram invertidas, de modo que todos os escores refletem linearmente a QV, sendo 1 a pior QV e 5 a melhor, tendo o valor 3 como intermediário. Esse ajuste matemático permite o cálculo das facetas que, agrupadas, resultam nos valores de cada domínio. Os escores variam de 4 a 20 pontos, refletindo a pior e melhor QV, respectivamente. Para análise da distribuição dos pacientes quanto aos escores dos domínios da QV foram estipuladas três posições: inferior (de 4 a 10 pontos), intermediária (de 10,1 a 14,9) e superior (de 15 a 20) 6,8-10.

Para coleta de dados sociodemográficos, clínicos e laboratoriais foi utilizado instrumento próprio. Os resultados de contagem de CD4+ e Carga Viral do HIV foram coletados nos prontuários médicos dos pacientes e o resultado considerado foi o de 30 dias antes ou depois da entrevista. Estes exames foram todos realizados pelo mesmo laboratório. A contagem de $\mathrm{CD} 4+$ foi realizada por citometria de fluxo e a carga viral (CV) do HIV foi quantificada pela técnica de amplificação baseada na sequência de ácidos nucléicos (NASBA ${ }^{\circledR}$ Organon Teknica, Boxtel, Holland), com limite para detecção acima de 50 cópias/ml.

A análise estatística foi realizada no software Bioestat 5.0. Foi utilizada estatística descritiva; teste Mann-Whitney para duas amostras independentes; e análise de variância com o teste ANOVA para um critério (a posteriori Tukey) ou Kruskal-Wallis (a posteriori Student-Newman-Keuls), de acordo com as variáveis analisadas. O nível de significância adotado foi de $\mathrm{p}<0,05$.

A pesquisa foi aprovada pelo Comitê de Ética da Universidade Federal de Mato Grosso do Sul sob o protocolo 27/2008 e os autores afirmam que não existe conflito de interesse na realização do presente estudo.

\section{Resultados}

A Tabela 1 sumariza a distribuição dos 205 participantes conforme os escores obtidos em cada domínio. Os escores das facetas são mostrados na Tabela 2. A avaliação da QV em relação a dados sociodemográficos está mostrada na Tabela 3, e em relação a dados clínicos e laboratoriais na Tabela 4.

A contagem de células CD4 apresentou diferença significante no domínio nível de independência, entre o grupo com 200 a 499 células e o grupo com $\geq 500(\mathrm{p}<0,01)$. O tempo de infecção apresentou associação com o domínio ERCP, sendo significativamente mais alta no grupo de 2,1 a 5 anos (Tabela 4).

A presença de outra doença concomitante à infecção pelo HIV afetou negativamente os domínios nível de independência e relações sociais, com melhor escore dos pacientes sem complicação paralela. O nível de independência também foi afetado 
Tabela 1 - Pacientes HIV/AIDS segundo domínios da qualidade de vida e as posições inferior, intermediária e superior. Campo Grande/MS - 2008 ( $n=205)$.

Table 1 - Patients with HIV/AIDS according to lower, intermediate and high levels of quality of life domains. Campo Grande/MS - $2008(n=205)$.

\begin{tabular}{lcccccc}
\hline \multirow{2}{*}{ Domínios } & \multicolumn{6}{c}{ Posições } \\
\cline { 2 - 7 } & \multicolumn{2}{c}{ Inferior $^{2}$} & \multicolumn{2}{c}{ Intermediária } & \multicolumn{2}{c}{ Superior $^{4}$} \\
\cline { 2 - 7 } & $\mathrm{N}^{\circ}$. & $\%$ & $\mathrm{~N}^{\circ}$. & $\%$ & $\mathrm{~N}^{\circ}$. & $\%$ \\
\hline Físico & 53 & 25,9 & 77 & 37,5 & 75 & 36,6 \\
Psicológico & 10 & 4,9 & 85 & 41,5 & 110 & 53,6 \\
Nível de independência & 28 & 13,7 & 133 & 64,8 & 44 & 21,5 \\
Relações sociais & 9 & 4,4 & 124 & 60,5 & 72 & 35,1 \\
Meio ambiente & 17 & 8,3 & 167 & 81,5 & 21 & 10,2 \\
ERCP(1) & 17 & 8,3 & 152 & 74,1 & 36 & 17,6 \\
\hline
\end{tabular}

(1)Espiritualidade, religiosidade e crenças pessoais. / Spirituality, religion and personal beliefs.

(2)De 4 a 10 pontos. / From 4 to 10 points.

${ }^{(3)}$ De 10,1 a 14,9 pontos. / From 10.1 to 14.9 points.

(4) De 15 a 20 pontos. / From 15 to 20 points.

negativamente pelo uso dos medicamentos antirretrovirais, sendo observada diferença significante entre aqueles que usavam os medicamentos e aqueles que não os utilizavam, que também apresentaram a melhor média nesse domínio (Tabela 4).

\section{Discussão}

As características sociodemográficas e clínicas da amostra são semelhantes às observadas nos pacientes adultos com HIV/ AIDS no Brasil e em outros países: amostra com maioria masculina, com trabalho e baixa renda, uso da HAART e baixa frequência de doenças concomitantes ao HIV ${ }^{4,5,7-9,11-14}$. Os escores médios obtidos para os seis domínios foram de 12,6 a 14,8 pontos, classificados como intermediários ${ }^{6}$.

PVHAs na Índia ${ }^{11}$ tiveram escores médios similares aos obtidos neste estudo, exceto no domínio meio-ambiente, superior ao encontrado por esse trabalho. Em outro estudo indiano ${ }^{8}$ foram encontrados escores superiores nos domínios da QV em comparação com os pacientes deste trabalho, com exceção do domínio relações sociais, que foi inferior.

De acordo com as faixas etárias, as melhores médias foram apresentadas pelos grupos mais jovens (de 20 a 39 anos).
PVHAs $^{12}$ também apresentaram a associação, sendo a das pessoas com até 35 anos as melhores médias, com significativa diferença das idades mais avançadas no domínio psicológico. De acordo com os dados deste estudo, existe comportamento negativo na relação entre a idade e a QV de PVHAs.

Santos et al. ${ }^{6}$ apontaram que os homens apresentam melhor QV que as mulheres, concordando com o presente estudo nos domínios físico, psicológico e ERCP. A compreensão dessas diferenças é mais bem entendida à luz do local de análise, pois na Índia ${ }^{8}$ as mulheres apresentam melhor QV e na Croácia ${ }^{12}$ não foram identificadas diferenças entre os sexos. Repressão religiosa e social, acesso a lazer e outros componentes sociais, bem como a garantia de direitos entre os sexos, incidem sobre os domínios.

A escolaridade apresentou associação com a QV, sendo que os pacientes sem nenhuma escolaridade tiveram as piores médias nos escores físico, psicológico, nível de independência, relações sociais e meio ambiente. Outros estudos observaram correlação entre QV e escolaridade ${ }^{6,12}$, evidenciando que investimentos em educação também podem influenciar a QV em PVHAs.

O estado civil apresentou associação com quatro domínios: físico, psicológico, nível de independência e relações sociais. 
Tabela 2 - Escores do questionário WHOQOL-120 HIV de 205 pacientes HIV/AIDS de acordo com as facetas e domínios. Campo Grande/MS - 2008 ( $n=205)$.

Table 2 - Scores of the WHOQOL-120 HIV questionnaire of 205 patients with HIV/AIDS according to facets and domains. Campo Grande/MS - $2008(n=205)$.

\begin{tabular}{|c|c|}
\hline Qualidade de vida & Média \pm DP* \\
\hline Físico & $13,1 \pm 3,5$ \\
\hline Dor & $3,0 \pm 1,1$ \\
\hline Energia & $3,3 \pm 1,1$ \\
\hline Sono & $3,7 \pm 1,3$ \\
\hline Sintomas $^{(1)}$ & $3,1 \pm 1,3$ \\
\hline Psicológico & $14,8 \pm 2,7$ \\
\hline Sentimentos positivos & $3,9 \pm 0,8$ \\
\hline Cognição & $3,4 \pm 1,0$ \\
\hline Auto-estima & $3,9 \pm 0,6$ \\
\hline Corpo & $4,0 \pm 1,0$ \\
\hline Sentimentos negativos & $3,1 \pm 1,2$ \\
\hline Nível de independência & $12,9 \pm 2,5$ \\
\hline Mobilidade & $3,3 \pm 0,7$ \\
\hline AVD ${ }^{(2)}$ & $3,7 \pm 1,1$ \\
\hline Dependência & $2,4 \pm 1,1$ \\
\hline Trabalho & $3,5 \pm 0,9$ \\
\hline Relações sociais & $14,0 \pm 2,2$ \\
\hline Relacionamentos & $3,7 \pm 1,0$ \\
\hline Apoio & $3,1 \pm 0,8$ \\
\hline Sexo & $3,5 \pm 0,8$ \\
\hline Inclusão(1) & $3,6 \pm 1,0$ \\
\hline Meio ambiente & $12,9 \pm 1,9$ \\
\hline Segurança & $2,8 \pm 0,9$ \\
\hline Moradia & $3,6 \pm 1,2$ \\
\hline Finanças & $3,2 \pm 0,7$ \\
\hline Cuidados & $3,4 \pm 1,2$ \\
\hline Informação & $3,3 \pm 1,0$ \\
\hline Lazer & $3,6 \pm 1,0$ \\
\hline Ambiente físico & $3,6 \pm 0,7$ \\
\hline Transporte & $2,6 \pm 1,1$ \\
\hline ERCP (3) & $12,6 \pm 2,4$ \\
\hline Perdão(1) & $3,2 \pm 0,8$ \\
\hline Futuro(1) & $3,1 \pm 0,8$ \\
\hline Morte $^{(1)}$ & $3,2 \pm 0,9$ \\
\hline $\mathrm{ERCP}^{(3)}$ & $3,1 \pm 0,7$ \\
\hline
\end{tabular}

* Desvio-padrão. / Standard deviation.

(1) Facetas específicas para as pessoas vivendo com HIV/AIDS. / Specific facets for persons living with HIV/AIDS.

(2) Atividades da vida diária./ Daily living activities.

${ }^{(3)}$ Espiritualidade, religiosidade e crenças pessoais. / Spirituality, religion and personal beliefs. 
Tabela 3 - Escore do questionário WHOQOL-120 HIV de 205 pacientes HIV/AIDS segundo dados sociodemográficos e os domínios da qualidade de vida. Campo Grande/MS - 2008 ( $n=205)$.

Table 3 - Score of the WHOQOL-120 HIV questionnaire of 205 patients with HIV/AIDS according to sociodemographic data and quality of life domains. Campo Grande/MS - 2008 ( $n=205)$.

\begin{tabular}{|c|c|c|c|c|c|c|}
\hline \multirow[t]{2}{*}{ Variáveis } & \multicolumn{6}{|c|}{ Escore médio de qualidade de vida (DP(1)) } \\
\hline & Físico & Psicológico & $\begin{array}{l}\text { Nível de } \\
\text { indep.(2) }\end{array}$ & $\begin{array}{c}\text { Relações } \\
\text { sociais }\end{array}$ & $\begin{array}{c}\text { Meio } \\
\text { ambiente }\end{array}$ & $\mathrm{ERCP}^{(3)}$ \\
\hline \multicolumn{7}{|l|}{ Idade } \\
\hline 20 a 29 anos $(n=31)$ & $12,9(2,7)$ & $14,1(2,3)^{*}$ & $13,9(2,2)^{*}$ & $14,9(2,2)^{*}$ & $12,8(1,5)^{*}$ & $12,4(2,6)$ \\
\hline 30 a 39 anos $(n=69)$ & $13,4(3,5)$ & $15,4(2,1)^{*}$ & $13,0(2,2)^{*}$ & $14,3(1,7)^{*}$ & $12,8(1,7)^{*}$ & $12,0(1,8)$ \\
\hline 40 a 49 anos $(n=65)$ & $12,4(4,0)$ & $14,2(3,2)^{*}$ & $12,7(2,5)^{*}$ & $13,2(2,5)^{*}$ & $12,1(2,1)$ & $12,6(2,9)$ \\
\hline 50 a 59 anos $(n=29)$ & $11,9(3,5)$ & $12,9(2,9)^{*}$ & $11,4(2,6)^{*}$ & $13,3(1,6)^{*}$ & $12,5(1,4)^{*}$ & $13,1(2,2)$ \\
\hline 60 anos e acima $(n=11)$ & $10,5(0,9)$ & $14,0(0,8)^{*}$ & $10,2(1,2)^{*}$ & $11,2(1,4)^{*}$ & $10,9(1,5)^{*}$ & $11,7(0,5)$ \\
\hline \multicolumn{7}{|l|}{ Sexo } \\
\hline Masculino $(n=141)$ & $13,1(3,5)^{*}$ & $14,9(2,2)^{*}$ & $12,8(2,6)$ & $13,8(2,0)$ & $12,6(1,6)$ & $12,7(2,3)^{*}$ \\
\hline Feminino $(n=64)$ & $11,6(3,5)^{*}$ & $13,2(3,2)^{*}$ & $12,4(2,7)$ & $13,4(2,7)$ & $12,0(2,2)$ & $11,8(2,5)^{*}$ \\
\hline \multicolumn{7}{|l|}{ Escolaridade } \\
\hline Nenhuma $(n=17)$ & $9,9(1,5)^{*}$ & $12,7(2,1)^{*}$ & $10,1(1,6)^{*}$ & $11,5(1,7)^{*}$ & $11,1(1,6)^{*}$ & $11,8(1,3)$ \\
\hline Ensino fundamental $(n=96)$ & $12,9(3,5)^{*}$ & $14,4(3,1)$ & $12,5(2,3)^{*}$ & $13,5(2,2)^{*}$ & $11,9(1,9)^{*}$ & $12,4(2,2)$ \\
\hline Ensino médio ( $n=64)$ & $13,4(3,5)$ & $14,9(2,1)^{*}$ & $13,3(2,7)^{*}$ & $14,6(2,1)^{*}$ & $13,2(1,5)^{*}$ & $12,7(3,1)$ \\
\hline Ensino superior $(n=28)$ & $11,8(3,9)$ & $14,2(2,4)$ & $13,2(1,9)^{*}$ & $13,5(1,8)^{*}$ & $13,1(1,4)^{*}$ & $12,3(1,4)$ \\
\hline \multicolumn{7}{|l|}{ Estado civil } \\
\hline Solteiro $(n=66)$ & $12,2(3,4)^{*}$ & $14,2(2,1)^{*}$ & $12,8(2,7)^{*}$ & $13,7(2,1)^{*}$ & $12,8(1,9)$ & $12,2(2,2)$ \\
\hline Vivendo como casado $(n=41)$ & $12,9(4,1)^{*}$ & $14,9(2,4)$ & $11,9(1,8)^{*}$ & $13,5(1,6)^{*}$ & $12,0(1,6)$ & $12,2(2,2)$ \\
\hline Casado $(n=40)$ & $14,3(3,3)^{*}$ & $15,0(2,3)^{*}$ & $14,0(2,1)^{*}$ & $15,3(2,1)^{*}$ & $12,6(1,6)$ & $13,2(2,3)$ \\
\hline Separado / divorciado $(n=29)$ & $11,3(3,2)^{*}$ & $13,9(3,9)$ & $12,2(2,8)^{*}$ & $13,1(2,6)^{*}$ & $12,3(2,0)$ & $12,7(3,1)$ \\
\hline Viúvo (n=29) & $12,3(3,0)$ & $13,7(3,1)^{*}$ & $11,8(2,1)^{*}$ & $12,5(1,9)^{*}$ & $12,0(1,8)$ & $11,9(2,0)$ \\
\hline \multicolumn{7}{|l|}{ Cor da pele } \\
\hline Parda $(n=116)$ & $12,3(3,5)$ & $13,9(2,8)^{*}$ & $12,6(2,7)$ & $13,5(2,4)$ & $12,3(1,8)$ & $12,2(2,6)$ \\
\hline Negra $(n=74)$ & $12,9(3,5)$ & $15,1(2,4)^{*}$ & $12,9(2,3)$ & $14,0(2,0)$ & $12,6(1,9)$ & $12,6(2,1)$ \\
\hline Branca $(n=15)$ & $13,8(3,8)$ & $14,8(2,5)$ & $11,7(1,7)$ & $13,6(1,9)$ & $12,2(1,1)$ & $12,7(1,9)$ \\
\hline \multicolumn{7}{|l|}{ Renda } \\
\hline Até $1 \mathrm{SM}^{(4)}(\mathrm{n}=121)$ & $12,3(3,4)$ & $14,1(2,7)^{*}$ & $12,6(2,6)^{*}$ & $13,5(2,4)^{*}$ & $11,8(1,7)^{*}$ & $12,3(2,5)$ \\
\hline De 1,1 a 2 SM $(n=56)$ & $13,2(3,6)$ & $14,4(2,8)^{*}$ & $12,3(2,0)^{*}$ & $13,7(2,0)^{*}$ & $13,1(1,5)^{*}$ & $13,0(2,4)$ \\
\hline De 2,1 a 3 SM ( $n=12)$ & $14,6(4,5)^{*}$ & $16,4(1,7)^{*}$ & $12,0(1,0)^{*}$ & $15,0(0,8)^{*}$ & $13,3(0,9)^{*}$ & $12,0(0,9)$ \\
\hline De 3,1 a 4 SM $(n=6)$ & $15,0(2,4)$ & $16,8(1,5)^{*}$ & $16,5(2,7)^{*}$ & $16,2(2,0)^{*}$ & $15,8(0,4)^{*}$ & $11,3(1,5)$ \\
\hline $4,1 \mathrm{SM}$ e mais $(n=10)$ & $10,4(2,7)^{*}$ & $13,8(1,3)^{*}$ & $14,0(2,7)^{*}$ & $13,5(1,4)^{*}$ & $12,8(1,0)^{*}$ & $11,5(0,7)$ \\
\hline \multicolumn{7}{|l|}{ Trabalha } \\
\hline $\operatorname{Sim}(n=112)$ & $13,5(3,4)^{*}$ & $15,2(2,2)^{*}$ & $13,4(1,9)^{*}$ & $14,5(1,9)^{*}$ & $13,3(1,5)^{*}$ & $12,6(2,4)$ \\
\hline Não (n=93) & $11,7(3,4)^{*}$ & $13,5(2,9)^{*}$ & $11,8(2,7)^{*}$ & $12,8(2,3)^{*}$ & $11,4(1,7)^{*}$ & $12,2(2,3)$ \\
\hline
\end{tabular}

(1) Desvio-padrão./ Standard deviation.

(2) Nível de independência./ Level of independence.

(3) Espiritualidade, religiosidade e crenças pessoais. / Spirituality, religion and personal beliefs.

${ }^{(4)}$ Salário mínimo em reais (R\$). / Minimal wage in Reais $(R \$)$.

* Associação da variável com a qualidade de vida $(p<0,05)$. / Association of the variable with quality of life $(p<0.05)$. 
Tabela 4 - Escore do questionário WHOQOL-120 HIV de 205 pacientes HIV/AIDS segundo dados clínicos e laboratoriais e os domínios da qualidade de vida. Campo Grande/MS - $2008(\mathrm{n}=205)$.

Table 4 - Score of the WHOQOL-120 HIV questionnaire of 205 patients with HIV/AIDS according to clinical and laboratory data and quality of life domains. Campo Grande/MS - $2008(n=205)$.

\begin{tabular}{|c|c|c|c|c|c|c|}
\hline \multirow[t]{2}{*}{ Variáveis } & \multicolumn{6}{|c|}{ Escore médio de qualidade de vida (DP(1) } \\
\hline & Físico & Psicológico & $\begin{array}{l}\text { Nível de } \\
\text { indep.(2) }\end{array}$ & $\begin{array}{c}\text { Relações } \\
\text { Sociais }\end{array}$ & $\begin{array}{c}\text { Meio } \\
\text { ambiente }\end{array}$ & $\mathrm{ERCP}^{(3)}$ \\
\hline \multicolumn{7}{|l|}{ Células CD4 células/mL } \\
\hline$<200(n=48)$ & $12,8(3,9)$ & $14,9(2,5)$ & $13,1(2,4)$ & $13,8(1,8)$ & $12,6(1,7)$ & $12,9(2,9)$ \\
\hline 200 a $499(n=103)$ & $12,7(3,5)$ & $14,3(2,7)$ & $12,1(2,4)^{*}$ & $13,5(2,2)$ & $12,3(1,6)$ & $12,4(2,3)$ \\
\hline$\geq 500(n=54)$ & $12,5(3,4)$ & $14,0(2,8)$ & $13,4(2,6)^{*}$ & $14,1(2,8)$ & $12,5(2,3)$ & $11,9(1,8)$ \\
\hline \multicolumn{7}{|l|}{ Carga viral cópias/mL } \\
\hline$<50(\mathrm{n}=115)$ & $12,9(3,8)$ & $14,4(2,9)$ & $12,3(2,4)$ & $13,5(2,1)$ & $14,5(1,8)$ & $12,2(2,4)$ \\
\hline 50 a $10.000(n=61)$ & $11,8(3,2)$ & $14,6(2,5)$ & $13,2(2,6)$ & $13,8(2,5)$ & $12,4(1,8)$ & $12,8(2,4)$ \\
\hline 10.001 a $100.000(n=25)$ & $12,8(3,2)$ & $14,0(2,2)$ & $13,2(2,4)$ & $14,5(2,4)$ & $12,2(1,5)$ & $12,4(1,7)$ \\
\hline$>100.000(n=4)$ & $15,0(0,8)$ & $15,8(0,5)$ & $13,8(1,5)$ & $15,0(2,0)$ & $11,8(3,5)$ & $12,0(4,0)$ \\
\hline \multicolumn{7}{|c|}{ Tempo de diagnóstico da infecção pelo HIV } \\
\hline$\leq 2$ anos $(n=40)$ & $11,5(2,9)$ & $13,7(3,4)$ & $12,3(2,5)$ & $13,6(2,0)$ & $12,2(1,9)$ & $12,0(2,6)^{*}$ \\
\hline De 2,1 a 5 anos $(n=73)$ & $13,2(3,8)$ & $14,3(2,6)$ & $12,9(2,5)$ & $14,0(2,2)$ & $12,6(1,6)$ & $13,2(2,7)^{*}$ \\
\hline De 5,1 a 8 anos $(n=57)$ & $12,5(2,4)$ & $15,1(2,2)$ & $12,3(2,4)$ & $13,2(2,3)$ & $12,3(2,0)$ & $11,7(1,7)^{*}$ \\
\hline De 8,1 a 18 anos $(n=35)$ & $13,2(3,7)$ & $14,2(2,6)$ & $13,1(2,6)$ & $14,1(2,5)$ & $12,5(1,9)$ & $12,5(2,2)$ \\
\hline \multicolumn{7}{|l|}{ Presença de outra doença } \\
\hline $\operatorname{Sim}(n=62)$ & $12,1(3,2)$ & $13,7(2,9)$ & $12,1(2,6)^{*}$ & $13,1(2,2)^{*}$ & $12,5(2,8)$ & $12,9(3,7)$ \\
\hline Não (n=143) & $12,9(3,7)$ & $14,8(2,4)$ & $12,9(2,4)^{*}$ & $13,9(2,3)^{*}$ & $12,6(1,9)$ & $12,4(2,2)$ \\
\hline \multicolumn{7}{|l|}{ Uso de antirretrovirais } \\
\hline $\operatorname{Sim}(n=182)$ & $12,8(3,6)$ & $14,6(2,7)$ & $12,5(2,4)^{*}$ & $13,6(2,1)$ & $12,5(1,8)$ & $12,4(2,4)$ \\
\hline Não (n=23) & $11,9(3,2)$ & $13,5(2,3)$ & $14,1(2,3)^{*}$ & $14,6(3,2)$ & $12,1(1,9)$ & $12,0(1,5)$ \\
\hline
\end{tabular}

(1) Desvio-padrão. / Standard deviation.

(2) Nível de independência./ Level of independence.

(3) Espiritualidade, religiosidade e crenças pessoais. / Spirituality, religion and personal beliefs.

* Associação da variável com a qualidade de vida $(p<0,05)$. / Association of the variable with quality of life $(p<0.05)$.

Os pacientes casados apresentaram as maiores médias, sendo as piores observadas nos indivíduos separados/divorciados ou viúvos. Essa associação já foi verificada ${ }^{12}$ no domínio relações sociais, justificado pelo provável maior apoio social desse grupo. É possível que os pacientes em relacionamento conjugal apresentem melhor suporte social e apoio, afetando positivamente a QV, exemplificado por mulheres casadas ou em união estável ${ }^{15}$.

Diferenças significantes no domínio meio ambiente entre as pessoas de pele branca e parda já foram observadas ${ }^{6}$, sendo que a classificação foi autorreferida. Os autores apontam que as diferenças sociais podem ser responsáveis pela melhor QV nesse domínio dos pacientes de pele branca sobre os de pele parda e negra. Neste estudo foi possível identificar diferença entre as pessoas de pele parda e as de pele negra no domínio psicológico, com melhor escore dos negros, discordando de achados prévios $^{6}$. Como no trabalho destes autores, este estudo foi realizado em serviço universitário de referência; logo, a QV dos indivíduos selecionados nesse estudo pode ter sido superestimada quando comparada com populações excluídas ou em serviços com recursos precários. 
A renda apresentou associação com a QV nos domínios físico, psicológico, nível de independência, relações sociais e meio-ambiente. As pessoas com renda de 3,1 a 4 salários-mínimos (SM) apresentaram os melhores escores nos domínios, com exceção do domínio ERCP, demonstrando um limite da influência financeira sobre a QV dos indivíduos estudados. Os pacientes que trabalhavam obtiveram melhores escores em todos os domínios, com exceção do ERCP. O bem-estar material e a renda podem afetar a QV, mas devem ser compreendidos em um universo de fatores que também compõe o conceito ${ }^{8,11,13,16}$.

Os pacientes em melhor condição do sistema imunológico, representada pela contagem de células $\geq 500 / \mathrm{mm}^{3}$, apresentaram melhor escore no domínio nível de independência que o grupo com contagem de células CD4 abaixo de 500 . Isso corrobora com observações de melhores escores em pacientes com níveis mais altos de células CD4 $+^{9,11}$. O domínio nível de independência tem o uso de medicamentos como uma das facetas que pontua negativamente. $\mathrm{O}$ diagnóstico e tratamento precoces são fatores que, ao permitir melhora imunológica e esquemas terapêuticos com menor número de medicamentos, podem influir positivamente na QV desses pacientes.

Já foi identificada associação da CV com o domínio físico ${ }^{9}$, com pior escore do grupo em transição do nível não identificável para o nível identificável. Essa mudança, com magnitude para afetar a QV do paciente, chama a atenção para manter os esforços de controlar a CV em nível não mensurável. Em outro estudo ${ }^{11}$ houve associação com os domínios físico, psicológico, nível de independência e meio ambiente, com piores médias no grupo com mais de um milhão de cópias virais. Apesar de o tratamento apresentar efeitos mais agressivos durante a alta replicação viral, esse estudo contou com a participação de pacientes assintomáticos; logo, os autores sugeriram uma compreensão mais ampla dos efeitos da CV e da contagem de células CD4 sobre a QV das PVHA. No presente estudo não foi identificada associação da CV com a QV, além do comportamento das médias ser difuso em relação às faixas analisadas.

É preciso pensar na QV como um estado multifatorial ${ }^{11}$; assim, a contagem de células CD4 e CV podem ser fatores de confusão, mas é consenso que pacientes com baixa contagem de CD4 e elevada CV são mais propensos a sintomas da doença, a infecções oportunistas e a uso de maior número de medicamentos que afetam a QV negativamente ${ }^{6,7,9,11}$. Exemplificando, apesar de a amostra estudada não ter apresentado associação entre a contagem de células CD4 com o domínio físico, é evidente que a queda na contagem de linfócitos CD4+ representa comprometimento do sistema imunológico, facilitando a instalação de uma infecção oportunista e afetando negativamente este domínio. Esse evento é conhecido como efeito em cadeia ${ }^{9}$, quando algo não associado estatisticamente à QV pode afetar a mesma por meio de outra variável.

O tempo de infecção pelo HIV apresentou associação com o domínio ERCP, com diferenças significantes entre os grupos $\leq 2$ anos, de 2,1 a 5 anos e de 5,1 a 8 anos. Esse domínio representa as crenças do indivíduo em forças exteriores, que em momentos de dificuldade pode ajudar o paciente a vencer obstáculos ${ }^{16}$, e a associação com o domínio meio ambiente já foi verificada ${ }^{6}$, com melhor escore do grupo de 2 a 5 anos de infecção. Neste domínio, o grupo com o mesmo tempo de infecção do presente estudo também apresentou a melhor média. Já o grupo com menor tempo de infecção esteve entre os piores escores em todos os domínios do WHOQOL-120 HIV. Esse paciente que ingressa no tratamento da infecção pelo HIV sofre alteração em sua rotina diária, com visitas ao médico e testes laboratoriais, além dos medicamentos. A infecção representa novos aspectos psicológicos sobre a aceitação da doença e as novas dinâmicas dos relacionamentos sociais a que está habituado, representando período com baixo nível de QV.

Na variável presença de outra doença (entre elas a citomegalovirose, hepatite, 
pneumonia, candidíase, toxoplasmose, diarréia e neurotoxoplasmose) foi observada associação com os domínios nível de independência e relações sociais, com o grupo sem outra doença atingindo melhor QV em ambos. Esses resultados concordam com estudos prévios ${ }^{6,12}$. A presença de outra doença pode favorecer a apresentação de outros sintomas e eventualmente utilizar um número maior de medicamentos, afetando negativamente a QV.

No instrumento WHOQOL-120 HIV, o uso de medicamentos ou dependência de tratamentos está relacionado ao domínio nível de independência ${ }^{14}$. No presente estudo, os pacientes que estavam em tratamento com a terapia antirretroviral apresentaram média inferior ao grupo que não estava usando os medicamentos, e a variável apresentou associação com o domínio. Já foi identificado impacto no componente físico para aqueles em terapia antirretroviral $^{9}$ e observados efeitos negativos dos medicamentos em seis meses de uso ${ }^{13}$, mas após esse tempo a QV atingiu níveis pré-terapia antirretroviral. Dessa forma, concluíram que o tratamento não apresenta efeitos negativos em longo prazo na QV.

\section{Considerações finais}

A qualidade de vida é um campo complexo e pode sofrer interferência de diversos fatores. Idade jovem, sexo masculino, escolaridade, estado civil casado, boa renda mensal, trabalhar, alto nível de linfócitos CD4+ e ausência de medicamentos antirretrovirais são fatores que apresentaram relação positiva com a qualidade de vida,

Com os dados deste estudo é possível perceber que análises isoladas de variáveis na tentativa de identificar aquelas que afetam a QV do paciente portador do HIV são pobres. Como já foi sugerido ${ }^{11}$, é possível compreender a QV do paciente de maneira ampla, para maior efetividade da análise.

\section{Referências}

1. Sepkowitz KA. AIDS - The first 20 years. $N$ Engl J Med. 2001; 344 (23), 1764-72.

2. Brasil. Ministério da Saúde. Secretaria da Vigilância em Saúde. Programa Nacional de DST/Aids. Boletim epidemiológico AIDS/DST Brasília; 2008, 5(1).

3. Weiss RA. Twenty-five years of human immunodeficiency virus research: successes and challenges. Clin Exp Immunol 2008; 152: 201-10.

4. Fleck MPA, Leal OF, Louzada S, Xavier M, Chachamovich E, Vieira G et al. Aplicação da versão em português do instrumento de avaliação de qualidade de vida da Organização Mundial da Saúde (WHOQOL-100). Rev Saúde Pública 1999; 33(2): 198-205.

5. Zimpel RR, Fleck MP. Quality of life in HIV-positive Brazilians: application and validation of the World Health Organization Quality of Life-HIV, Brazilian version. AIDS Care 2007; 19(7): 923-30.

6. Santos ECM, França Junior I, Lopes F. Qualidade de vida de pessoas vivendo com HIV/Aids em São Paulo. Rev Saúde Pública 2007; 41(S2): 64-71.

7. Wig N, Lekshmi R, Pal H, Ahuja V, Mittal CM, Agarwal SK. The impact of HIV/AIDS on the quality of life: a cross sectional study in North India. Indian J Med Sci. 2006; $60(1): 3-12$
8. Chandra PS, Satyanarayana VA, Satishchandra P, Satish KS, Kumar M. Do Men and women with HIV differ in their quality of life? A study from South India. AIDS Behav 2008; 13(1): 110-7.

9. Gill CJ, Griffith JL, Jacobson D, Skinner S, Gorbach SL, Wilson IB. Relationship of HIV viral loads, CD4 counts, and HAART use to health-related quality of life. JAIDS 2002; 30(5): 485-92.

10. Hammer SM, Saag MS, Schechter M, Montaner JSG, Schooley RT, Jacobsen DM, et al. Treatment for adult HIV infection: 2006 recommendations of the International AIDS Society-USA Panel. JAMA 2006; 296(7): 827-43.

11. Chandra PS, Gandhi C, Satishchandra P, Kamat A, Desai A, Ravi V, et al. Quality of life in HIV subtype C infection among asymptomatic subjects and its association with CD4 counts and viral loads - a study from South India. Qual Life Res 2006; 15: 1597-605.

12. Kovacevic SB, Vurusic T, Duvancic K, Macek M. Quality of life of HIV-infected persons in Croatia. Coll. Antropo. 2006; 30(S2): 79-84.

13. Liu C, Weber K, Robison E, Hu Z, Jacobson LP, Gange SJ. Assessing the effect of HAART on change in quality of life among HIV-infected women. AIDS Research and Therapy 2006; 3(6). 
14. WHOQOL HIV Group. WHOQOL-HIV for quality of life assessment among people living with HIV and AIDSresults from the field test. AIDS Care. 2004; 16(7): 882-9.

15. Galvão LLF, Farias MCS, Azevedo PRM, Vilar MJP, Azevedo GD. Prevalência de transtornos mentais comuns e avaliação da qualidade de vida no climatério. Rev Assoc Med Bras 2007; 53(5): 414-20.
16. Peterson M, Webb D. Religion and spirituality in quality of life studies. Appl Res Quality of Life 2006; 1, 107-16.

Recebido em: 14/02/11

Versão final apresentada em: 09/08/11

Aprovado em: 02/09/11 